\title{
Dear Members of the Association
}

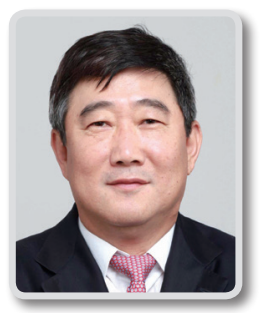

Kun Chul Yoon

President of Korean Cleft Palate-Craniofacial Association

My name is Kun-Chul Yoon. I have been elected as the next president of the Korean Cleft Palate-Craniofacial Association (KCPCA) for 2018.

The KCPCA successfully held its 20th annual conference in Seoul last November. On behalf of the association as well as the former Secretary Chairman Byung-Il Lee and former President Chul-Hoon Chung, I would like to express my sincere appreciation to Prof. NIls-Claudis Gellrich and Prof. Bohdan-Pomahac, and the Taiwan Society of Plastic Surgery and other international lecturers for their presence and support for the success of the meeting.

Over the last two decades, KCPCA, as a subsidiary unit of the Korea Society of Plastic and Reconstructive Surgeons, has pioneered cleft lip and palate treatments in Korea. Now, our association has grown to gain a brilliant reputation for developing craniofacial surgery beyond the Asia over the world as a result of continuous accomplishments made by its members including seniors, colleagues, and juniors. Among them the role of Archives of Craniofacial Surgery (ACFS) was outstanding. We had the pleasure to share the good news that ACFS had been in PUB-med.

I would like to thank all the editors of ACFS and particularly Editorial Director Prof. Kwang Seog Kim for their hard work.
As you may know, our association plans to hold a series of workshops and seminars in addition to the annual meeting in 2018. These events will provide our members with new learning experiences. Our enthusiastic participation in these meetings will unify and encourage us to be armoured strongly to compete with other groups of similar occupation in these challenging medical atmosphere.

Like other plastic surgery the aims of craniofacial surgery has both esthetic and reconstructive aspects. In performing our job we are always confronted to make decisions regarding the standards for aesthetics and the indications of applications. Eventhough we are living in the world of materialism, ethics as a doctor is a very crucial element of our profession. Members of our society should have a high standard of ethics and should not be influenced by excessive commercialism.

I have high expectations for the future of KCPCA and believe that all members will join in continued success of the association, as well as scholarly efforts through close cooperation. I personally wish you all the best and prosperous future. I also sincerely thank you for giving me the opportunity to serve as the President of the Association. 